CORRECTION

https://doi.org/10.1038/s41586-018-0369-7

\title{
Author Correction: Choosing the future of Antarctica
}

S. R. Rintoul, S. L. Chown, R. M. DeConto, M. H. England,

H. A. Fricker, V. Masson-Delmotte, T. R. Naish, M. J. Siegert \&

J. C. Xavier

Correction to: Nature https://doi.org/10.1038/s41586-018-0173-4, published online 13 June 2018.

On page 234 of this Perspective, ' $50 \%$ decrease' has been corrected online to ' $50 \%$ increase' in the sentence "The $\mathrm{pH}$ of surface waters south of $60^{\circ} \mathrm{S}$ decreased by 0.2 between 2017 and 2070 , equivalent to a $50 \%$ increase in the concentration of hydrogen ions since the pre-industrial period $^{1} .$. 